\title{
Psychiatric illness, emotional distress, glycemic control and chronic complications in type 1 diabetes subjects
}

${ }^{1}$ Programa de Endocrinologia, Universidade Federal do Rio Grande do Sul (UFRGS) Porto Alegre, RS, Brasil 2 Divisão de Endocrinologia, Hospital Escola, Universidade Federal de Pelotas (UFPEL), Pelotas, RS, Brasil ${ }^{3}$ Universidade Federal de Pelotas (UFPEL), Pelotas, RS, Brasil ${ }^{4}$ Universidade Federal do Rio Grande do Sul (UFRGS), Porto Alegre, RS, Brasil

${ }^{5}$ Divisão de Endocrinologia, Hospital de Clínicas de Porto Alegre (HCPA), Porto Alegre, RS, Brasil
Correspondence to:

Thiago Malaquias Fritzen Rua Teixeira Soares, 885, sala 1.001 99010-080 - Passo Fundo, RS, Brasil thiagofritzen@hotmail.com

Received on Oct/20/2020 Accepted on Apr/29/2021

DOI: 10.20945/2359-3997000000386
Thiago Malaquias Fritzen'

https://orcid.org/0000-0003-1995-0746

Letícia Schwerz Weinert²

https://orcid.org/0000-0002-2215-4743

Isabele Beatris Denk ${ }^{3}$

https://orcid.org/0000-0003-1854-0286

João Alberto Succolotti Deuschle ${ }^{3}$

https://orcid.org/0000-0002-2822-6891

Isabel Conte 4

https://orcid.org/0000-0003-4176-9505

Maurício Picolo Menegolla 4

https://orcid.org/0000-0002-4318-5194

Ticiana da Costa Rodrigues ${ }^{5}$

https://orcid.org/0000-0001-9254-3712

\begin{abstract}
Objectives: To assess the prevalence of psychiatric disorders in patients with type 1 diabetes mellitus (T1D) and to compare patients with and without psychiatric disorder. Materials and methods: We made a cross-sectional study including patients with T1D assisted in the outpatient clinics of the Brazilian National Health System. To assess depression and anxiety, we used the PHO-9 questionnaire and the DSM-5th edition criteria, respectively. B-PAID evaluated the level of emotional distress associated with diabetes; EAT-26, eating disorders; $\mathrm{SCl}-\mathrm{R}$, adherence to the proposed clinical treatment. Results: We analyzed 166 patients aged $33(22-45.2)$ years, $53.6 \%$ female. The prevalence of depression and anxiety was $20.5 \%$ and $40.4 \%$, respectively. $\mathrm{HbA} 1 \mathrm{c}$ was worse in the depressed $(9.0 \%$ vs. $8.4 \%, \mathrm{p}=$ $0.008)$, in the anxious ones $(9.0 \%$ vs. $8.3 \%, p=0.012)$ and in the patients with high levels of B-PAID ( 8.8 $\%$ vs. $8.3 \%, p=0.009$ ). There was no difference in the prevalence of complications related to diabetes. Conclusions: The prevalence of psychiatric disorders and emotional distress related to diabetes was high in our population ofT1D patients, and depression and high levels of B-PAID were associated with the worse glycemic control. Arch Endocrinol Metab. 2021;65(6):684-94
\end{abstract}

\section{Keywords}

Type 1 diabetes, psychiatric disorders; anxiety, depression, diabetes complication

\section{INTRODUCTION}

$\mathrm{T}$ ype 1 diabetes mellitus (T1D) is a chronic autoimmune disease that causes absolute deficiency in insulin production. People with the disease need daily insulin doses and glycemic self-monitoring several times a day, in addition to healthy living habits, with a routine of diet and physical activity. This demand for continuous self-care is especially difficult in childhood and adolescence. The transition to adulthood, in addition to impacting psychological maturity and increasing independence, commonly leads to worsening of the metabolic control of diabetes (1), increasing the prevalence of psychiatric disorders in this transition phase (2).

According to WHO data, depressive disorder affects about $4.4 \%$ of the world population, while the estimated prevalence of anxiety is $3.6 \%$ (3). Suicide accounts for $1.5 \%$ of all deaths, being among the 20 main causes of general mortality (3). Among patients with diabetes, several studies show higher rates of depression and anxiety than in the general population (4-6). Diabetes distress, a specific emotional disorder related to the underlying disease $(7,8)$, has an estimated prevalence of $18 \%$ to $45 \%$, depending on the geographic population 
evaluated (9), being the most common psychological disorder. Approximately 20\% of men and 30\% of women with TID have an eating disorder $(10)$, which is associated with poor glycemic control and an increased risk of developing diabetes complications (11-13). Likewise, the risk of suicide is higher in the diabetic population compared to controls. Rates of $9 \%$ suicidal ideation and 16\% suicide attempts were reported in a cohort of patients with TlD (14).

The aim of this study was to evaluate the prevalence of psychiatric disorders in patients with TID and its relationship with adherence to treatment, emotional distress related to diabetes control, metabolic rate and increased risk of related complications in the short and long term in a cohort of patients in southern Brazil.

\section{MATERIALS AND METHODS}

\section{Study design and population}

Cross-sectional study carried out in specialized care clinics at two university centers in the cities of Pelotas and Porto Alegre, southern Brazil - Federal University of Pelotas and Federal University of Rio Grande do Sul. Patients with TID who had performed more than 2 consultations registered in medical records, the last service being performed in the previous 12 months. The recruitment of patients took place from March 2016 to October 2019.

Patients under 10 years of age, those with other types of diabetes, those who had no registered consultation in the last 12 months or who did not agree to participate in the study were excluded.

The diagnosis of TID was made by a specialist doctor using clinical and laboratory criteria, such as a history of diabetic ketoacidosis, exclusive treatment with insulin, presence of positive glutamic acid anti-decarboxylase antibody or $\mathrm{C}$ peptide below the reference value.

The research project was submitted to and approved by the ethics committees of the Medical School of the Federal University of Pelotas (approval number 2.994.677) and the Hospital de Clinicas de Porto Alegre (approval number 2.762.272). CAAE number 91767018.9.1001.5327.

All participants signed an informed consent form.

\section{Covariables and questionnaires}

The variables under study were collected by previously trained interviewers, and data collection took place in three phases: 1. application of a face-to-face questionnaire to obtain socio demographic data, 2. three self-administered questionnaires previously standardized and translated into Portuguese (15-17) addressing aspects of the patient's relationship with diabetes and their current emotional situation; and 3. review of medical records to obtain clinical and laboratory data. The sampling was for convenience and consecutive, as scheduled for consultations. Participants from the Porto Alegre group were interviewed in a single approach, while those from Pelotas were interviewed in 2 different meetings, simultaneous to the consultations.

The clinical information obtained from the medical record was the presence of macrovascular disease (acute myocardial infarction [AMI], peripheral arterial obstructive disease or stroke), systemic arterial hypertension, dyslipidemia, kidney disease, diabetic neuropathy and retinopathy and hypoglycemia.

The laboratory tests evaluated in medical records within the last 12 months, were: glycated hemoglobin, the most recent (HbAlc, High performance liquid chromatography, HPLC), urine sample albuminuria (immunoturbidimetry), serum creatinine (colorimetric method), thyroid function (immunoassay of microparticles by chemiluminescence), antibodies to celiac disease (chemiluminescence method), antiglutamic acid decarboxylase antibody (anti GAD, enzyme immunoassay method) and $\mathrm{C}$ peptide (microparticle chemiluminescent immunoassay).

Those ones with a medical record of the event were considered with macrovascular disease. Patients admitted as hypertensive and dyslipidemic were using antihypertensive and hypolipidemic medication, respectively. Participants who had albuminuria in isolated urine sample $>30 \mathrm{mg} / \mathrm{g}$ creatinine and/ or estimated glomerular filtration (eGFR) $<60 \mathrm{~mL} /$ $\mathrm{min} / 1.73 \mathrm{~m}^{2}$ (Chronic Kidney Disease Epidemiology Collaboration, CKD-EPI) in two different times were considered renal patients $(18,19)$. The diagnosis of diabetic neuropathy and diabetic retinopathy were obtained through medical records, since SemmesWeinstein $10 \mathrm{~g}$ monofilament neuropathy test and the fundus examination of the eye are performed annually. Glycemia events $\leq 70 \mathrm{mg} / \mathrm{dL}$ were considered hypoglycemia (20), severe when needed the help of third parties for management; frequent when 3 or more weekly and night events occurred was related to 1 or more weekly episodes obtained from clinical information directly from the patient. Those patients 
who reported practicing at least 150 minutes of weekly physically activity were considered physically active.

Participants were asked about their previous diagnosis of psychiatric disorder indicating which disease(s) they had: depression, anxiety, panic disorder, bipolar disorder, "I don't know" - when they didn't know their psychiatric diagnosis - and "other", when the pathology was not included in the presented relation. For objective evaluation, the Brazilian Problem Areas In Diabetes Scale (B-PAID) questionnaires, related to the level of emotional distress associated with the routine of living with diabetes, with values $\geq 40$ indicating high level of emotional distress, considered "Severe B-PAID" (15). Eating Attitudes Test-26 (EAT-26), to access eating disorders (21) and Self Care Inventory - Revised Version (SCI-R) to estimate the degree of adherence to the proposed clinical treatment (17). The three questionnaires are validated for Portuguese (15-17). A participant with a score $\geq$ 10 on the Patient Health Questionnaire - 9 (PHQ-9) (22), validated for the Brazilian population (23), was considered to have a depressive disorder. The screening for anxiety was performed using the DSM-5th edition criteria (24). The two last one's screenings were used in this article to classify depressive and anxious patients. Participants were asked about the monthly family income, in minimum wages (the brazilian minimum wage is equivalent to US\$ 200 dollars). Regarding drug use (licit or illicit) participants were considered users who self-reported routine use, without quantification. Patients were approached about ideation and/or attempted suicide through a direct question: "Have you ever had suicidal ideation or attempted suicide?".

\section{Statistical analysis}

For statistical analysis and graphic representation, we used the program Statistical Package for the Social Sciences (SPSS, IBM Corp. and its licensors) for Windows (version 22). Dichotomous variables were described as number and percentage, and quantitative variables were defined as mean, standard deviation, median and interquartile range according to the Gaussian distribution. Comparisons were made using $t$ test for variables with normal distribution, and Mann-Whitney test for non-Gaussian distribution for continuous variables, and chi-square and Fisher's exact for qualitative variables. Logistic and linear regression models were used to assess possible effects of other additional risk factors. The level of significance adopted was $5 \%$.

\section{Sample calculation}

The sample calculation was based on a Brazilian study with TID patients, whose prevalence of depression was $13.6 \%$ with a sample size of 181 patients being defined, assuming $5 \%$ as the maximum difference between the prevalence of real depression and estimated, with a $95 \%$ confidence level.

\section{RESULTS}

Altogether, 191 patients met the inclusion criteria, with 25 being excluded for not completing the clinical interview. Among the participants, 120 came from the Porto Alegre outpatient clinic and 46 from Pelotas. Regarding the patients excluded from the study $(\mathrm{n}=25)$, they were younger with a median of 21 years (15.0-27.5), had shorter disease duration and a higher level of $\mathrm{HbAlc} 9.4 \%$ [7.5\%-12.1\%], (79 mmol/mol [58-109]), than the patients included in the study. The other variables were not different. (Supplement).

The analysis of the 166 patients included showed that $89(53.6 \%)$ were women, with a median of 14 years of disease duration, HbAlc median of $8.5 \%$ (7.8\%$9.4 \%),(69 \mathrm{mmol} / \mathrm{mol}$ [62-79]), and monthly family income of 2 (1-3) minimum wages (Supplement). All those included used a basal/bolus insulin regimen, with 91 (54.8\%) using NPH (Neutral Protamine Hagedorn) insulin, while the others used insulin glargine, $\mathrm{n}=75(45.2 \%)$, as basal therapy. Of the prandial insulins, 111 (66.9\%) used rapid-acting insulin analogues (lispro, aspart or glulisine) and the remaining patients used regular human insulin. Only one patient was an intermittent insulin pump user. Of those who used a basal/bolus regimen, 119 (71.7\%) made 2 to 4 applications a day, with $136(81.9 \%)$ reusing needles and/or syringes three or more times. Almost all patients checked capillary blood glucose daily, $\mathrm{n}=156$ (94\%), with $137(82.5 \%)$ taking 3 or more tests a day. Only $18(10.8 \%)$ patients had excellent glycemic control (HbAlc $\leq 7.0 \%$ or $53 \mathrm{mmol} / \mathrm{mol}$ ) (9).

The prevalence of some psychiatric disorder in the sample studied was $\mathrm{n}=91$ (54.8\%), with $67(40.4 \%)$ patients having positive screening for anxiety and 34 $(20.5 \%)$ for depressive disorder, exclusively (Figure 1). Of the 91 patients with positive screening, $62(68.1 \%)$ had already been evaluated by psychologists/ psychiatrists at some point in their lives. Psychiatric drug users were 45 (27.1\%), of 166 participants. 


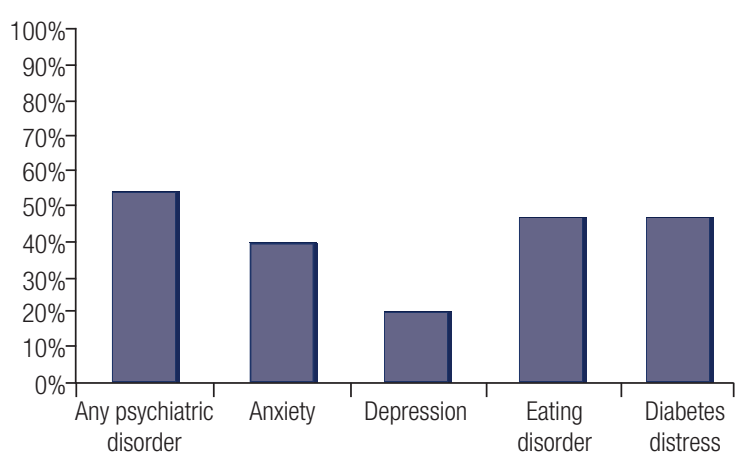

Figure 1. Prevalence of Psychiatric Disorders in Patients with T1D.

A comparative analysis was performed between the groups of patients with and without depression assessed by PHQ-9, which are described in Table 1. Glycemic control, assessed by measuring $\mathrm{HbAlc}$, was worse in depressed patients $(9.0 \%$ vs. $8.45 \%, p=0.008),(75$ $\mathrm{mmol} / \mathrm{mol}$ vs. $69 \mathrm{mmol} / \mathrm{mol})$, requiring greater family $\operatorname{support}(23[67.6 \%]$ vs. $63[47.7 \%], \mathrm{p}=0.038)$ in relation to controls. No statistically significant differences were found in acute and chronic complications related to diabetes in relation to the presence of depression, although depressed patients were more prone to severe hypoglycemia $(23[67.6 \%]$ vs. $74[56.1 \%], \mathrm{p}=0.22)$ and had greater need for hospitalization due to the diabetes (22 [64.7\%] vs. 75 [56.8\%], $\mathrm{p}=0.405)$. We assessed, through correlation, possible factors associated with glycemic control and observed only a weak correlation with income $(\mathrm{r}=0.206, \mathrm{p}=0.002)$. The other factors were not correlated. In the multiple regression analysis using $\mathrm{HbAlc}$ as the main outcome and adjustment for diabetes time, we found that the presence of depression was associated with the worse glycemic control $(\beta=$ $0.202 ; \mathrm{p}=0.013$, CI 95\% 0.177-1.485).

Table 1. Demographic characteristics of type 1 diabetic patients with or without depression $(n=166)$

\begin{tabular}{|c|c|c|c|c|}
\hline Variable & & Depression $(n=34)$ & Without Depression $(n=132)$ & p \\
\hline Age, years & & $34(28-45.5)$ & $33(21-45.5)$ & 0.327 \\
\hline Age of diagnosis, years & & $14.5(11.7-27.2)$ & $18(11-25)$ & 0.773 \\
\hline Years with T1D & & $18(7.7-25.2)$ & $12(5-25)$ & 0.176 \\
\hline Body mass index & & $24.9 \pm 4.6$ & $24.9 \pm 4.1$ & 0.694 \\
\hline \multirow[t]{2}{*}{ Glycated hemoglobin } & $\%$ & $9(8.4-10.3)$ & $8.4(7.7-9.2)$ & 0.008 \\
\hline & $\mathrm{mmol} / \mathrm{mol}$ & $74.8(68.3-89.1)$ & $68.3(60.6-77)$ & \\
\hline \multicolumn{5}{|l|}{ Gender } \\
\hline Female & & $21(61.8)$ & $68(51.5)$ & 0.285 \\
\hline Skin Color & & & & 0.226 \\
\hline White & & 26 (76.5) & $116(87.9)$ & \\
\hline Black & & $5(14.7)$ & $11(8.3)$ & \\
\hline Brown & & $3(8.8)$ & $5(3.8)$ & \\
\hline Nephropathy & & $10(29.4)$ & $28(21.4)$ & 0.321 \\
\hline Neuropathy & & $8(23.5)$ & $16(12.1)$ & 0.092 \\
\hline Vasculopathy & & $4(11.8)$ & $7(5.3)$ & 0.177 \\
\hline Diabetic retinopathy & & $10(29.4)$ & $44(33.3)$ & 0.789 \\
\hline Dyslipidemia & & $10(29.4)$ & $25(18.9)$ & 0.182 \\
\hline Hypertension & & $11(32.4)$ & $40(30.3)$ & 0.860 \\
\hline \multicolumn{5}{|l|}{ Hypoglycemia } \\
\hline Severe & & $23(67.6)$ & $74(56.1)$ & 0.222 \\
\hline Frequent & & $11(32.4)$ & 27 (20.5) & 0.141 \\
\hline Nocturnal & & $18(52.9)$ & $50(37.9)$ & 0.111 \\
\hline Previous ICU admission & & $13(38.2)$ & $58(43.9)$ & 0.549 \\
\hline Diabetes hospitalization & & $22(64.7)$ & $75(56.8)$ & 0.405 \\
\hline Family support & & $23(67.6)$ & $63(47.7)$ & 0.038 \\
\hline Physical activity & & $10(29.4)$ & $58(43.9)$ & 0.125 \\
\hline
\end{tabular}




\begin{tabular}{lccc}
\hline Variable & Depression $\mathbf{( n = 3 4 )}$ & Without Depression $\mathbf{( n = 1 3 2 )}$ & $\mathbf{p}$ \\
\hline Glucose self-monitoring & $31(91.2)$ & $125(94.7)$ & 0.442 \\
Psychiatric medication & $19(55.9)$ & $26(19.7)$ & $<\mathbf{0 . 0 0 1}$ \\
Psychological assessment & $30(88.2)$ & $59(44.7)$ & $<\mathbf{0 . 0 0 1}$ \\
Drugs & & & 0.116 \\
$\quad$ Alcohol & $3(8.8)$ & $27(20.5)$ & 0.638 \\
Cigarette & $4(11.8)$ & $12(9.1)$ & $\mathbf{0 . 0 0 5}$ \\
Cocaine & $2(5.9)$ & $18(13.6)$ & $<0.001$ \\
Suicidal & $18(52.9)$ & $58(43.9)$ & 0.063 \\
EAT $\geq 21$ & $21(61.8)$ & $77(58.3)$ & 0.073 \\
SCI-R $>$ 48 & $14(41.2)$ & $35(14.1-55)$ & $<0.001$ \\
B-PAID, punctuation & $60.6(39.3-71.2)$ & $44(33.3)$ & $<$ \\
Anxiety & $23(67.6)$ & & $<.001$ \\
\hline
\end{tabular}

Data are presented as median (interquartile range), means \pm standard deviation and number of patients (percentual).

Psychiatric medication means current treatment. Psychological assessment corresponds to assessment at any time in the past.

The comparison between groups of patients with and without anxiety (Table 2), on the other hand, also demonstrated that anxious patients have the worse glycemic control $(9.0 \%[8.3 \%-9.6 \%]$ vs. $8.3 \%[7.8 \%$ $9.1 \%], \mathrm{p}=0.012),(75 \mathrm{mmol} / \mathrm{mol}[67-81]$ vs. 67 $\mathrm{mmol} / \mathrm{mol}[62-76])$. In addition, anxiety was more frequent in females $(45[67.2 \%]$ vs. 44 [44.4\%], p = $0.004)$, in participants with ideation or suicide attempts (26 [38.8\%] vs. $10[10.1 \%]), \mathrm{p}<0.001)$ and it was lower in physical activity practitioners (18 [26.9\%] vs.
$50[50.5 \%], \mathrm{p}=0.002)$ compared to patients without anxiety. The other variables showed no significant difference. After regression adjusted for sex, physical activity and diabetes duration, anxiety was not associated with the worse glycemic control.

As for the eating disorder, 79 (47.6\%) patients had positive EAT screening. The group of patients with positive screening had an older age, were more frequently female, had a higher rate of clinical comorbidities and a higher level of suffering from B-PAID (Table 3 ).

Table 2. Demographic characteristics of type 1 diabetic patients with or without anxiety $(n=166)$

\begin{tabular}{|c|c|c|c|c|}
\hline Variable & & Anxiety $(n=67)$ & Without Anxiety $(n=99)$ & $\mathbf{p}$ \\
\hline Age, years & & $33(24-47)$ & $33(19-45)$ & 0.507 \\
\hline Age of diagnosis, years & & $17(12-25)$ & $16(11-26)$ & 0.557 \\
\hline Years with T1D & & $15(6-25)$ & $14(6-25)$ & 0.699 \\
\hline Body mass index & & $24.8 \pm 4.2$ & $25 \pm 4.3$ & 0.682 \\
\hline \multirow[t]{2}{*}{ Glycated hemoglobin } & $\%$ & $9.0(8.3-9.6)$ & $8.3(7.8-9.1)$ & 0.012 \\
\hline & $\mathrm{mmol} / \mathrm{mol}$ & $74.8(67.2-81.4)$ & $67.2(61.7-75.9)$ & \\
\hline \multicolumn{5}{|l|}{ Gender } \\
\hline Female & & $45(67.2)$ & $44(44.4)$ & 0.004 \\
\hline Skin Color & & & & 0.394 \\
\hline White & & $55(82.1)$ & 87 (87.9) & \\
\hline Black & & $9(13.4)$ & $7(7.1)$ & \\
\hline Brown & & $3(4.5)$ & $5(5.1)$ & \\
\hline Nephropathy & & $20(29.9)$ & $18(18.4)$ & 0.085 \\
\hline Neuropathy & & $13(19.4)$ & $11(11.1)$ & 0.136 \\
\hline Vasculopathy & & $6(9)$ & $5(5.1)$ & 0.321 \\
\hline Diabetic retinopathy & & $23(34.3)$ & $31(31.3)$ & 0.666 \\
\hline Dyslipidemia & & $12(17.9)$ & $23(23.2)$ & 0.41 \\
\hline Hypertension & & $20(29.9)$ & $31(31.3)$ & 0.471 \\
\hline
\end{tabular}




\begin{tabular}{|c|c|c|c|}
\hline Variable & Anxiety $(n=67)$ & Without Anxiety ( $n=99)$ & p \\
\hline \multicolumn{4}{|l|}{ Hypoglycemia } \\
\hline Severe & $44(65.7)$ & $53(53.5)$ & 0.12 \\
\hline Frequent & $18(26.9)$ & $20(20.2)$ & 0.316 \\
\hline Nocturnal & 29 (43.3) & 39 (39.4) & 0.617 \\
\hline Previous ICU admission & $31(46.3)$ & $40(40.4)$ & 0.454 \\
\hline Diabetes hospitalization & $40(59.7)$ & $57(57.6)$ & 0.785 \\
\hline Family support & $40(59.7)$ & $46(46.5)$ & 0.094 \\
\hline Physical activity & $18(26.9)$ & $50(50.5)$ & 0.002 \\
\hline Glucose self-monitoring & $60(89.6)$ & $96(97)$ & 0.049 \\
\hline Psychological assessment & $43(64.2)$ & $46(46.5)$ & 0.025 \\
\hline Psychiatric medication & $25(37.3)$ & $20(20.2)$ & 0.015 \\
\hline \multicolumn{4}{|l|}{ Drugs } \\
\hline Alcohol & $12(17.9)$ & 18 (18.2) & 0.964 \\
\hline Cigarette & $7(10.4)$ & $9(9.1)$ & 0.771 \\
\hline Cocaine & $2(3)$ & . & 0.084 \\
\hline Suicidal & $26(38.8)$ & $10(10.1)$ & $<0.001$ \\
\hline EAT $\geq 21$ & $34(50.7)$ & $45(45.5)$ & 0.503 \\
\hline $\mathrm{SCl}-\mathrm{R}>48$ & $31(46.3)$ & $60(60.6)$ & 0.069 \\
\hline B-PAID, punctuation & $56.2(37.5-70)$ & $25(11.2-47.5)$ & $<0.001$ \\
\hline Depression & $23(34.3)$ & $11(11.1)$ & $<0.001$ \\
\hline
\end{tabular}

Data are presented as median (interquartile range), means \pm standard deviation and number of patients (percentual).

Psychiatric medication means current treatment. Psychological assessment corresponds to assessment at any time in the past.

The B-PAID instrument diagnosed $79(47.6 \%)$ patients with high emotional load, with glycemic control being worse in this group. The group with the greatest emotional distress had a higher percentage of women and more patients with positive screening for eating disorder. The individuals most adherent to the treatment were in the group with the lowest emotional distress and those who practiced regular physical activity had significantly lower levels of emotional distress (Table 4). B-PAID maintained an association with worse glycemic control after adjusting for sex and regular physical activity after multiple regression analysis $(\beta=0.2 ; \mathrm{p}=0.018$, CI 95\% 0.117-1.212).
Treatment adherents totaled 91 (54.8\%) using the SCI-R questionnaire. The group with adhesion showed better levels of glycated hemoglobin (8.4\% [7.5\%-9.1\%] vs. $8.8 \%[8.0 \%-9.6 \%], \mathrm{p}=0.023),(68 \mathrm{mmol} / \mathrm{mol}$ [58-76] vs. $73 \mathrm{mmol} / \mathrm{mol}[64-81])$, more frequent physical activity $(50[54.9 \%]$ vs. $18[24 \%], \mathrm{p}<0.001)$, more self-blood glucose monitoring $(90$ [98.9\%] vs. 66 [88\%], $\mathrm{p}=0.003$ ) and lower frequency of psychiatric medication use (18 [19.8\%] vs. 27 [36\%], p = 0.019) in relation to patients poorly adherent. Smoking was more frequent in TID patients with low adherence to treatment when compared with adherents (11 [14.7\%] vs. $5[5.5 \%], \mathrm{p}=0.046)$ (Supplement).

Table 3. Demographic characteristics of type 1 diabetic patients at EAT Questionnaire ${ }^{1}(n=166)$

\begin{tabular}{|c|c|c|c|c|}
\hline Variable & & Eating disorder $(n=79)$ & Negative eating disorder $(n=87)$ & p \\
\hline Age, years & & $37(24-50)$ & $31(21-39)$ & 0.022 \\
\hline Age of diagnosis, years & & $18(11-26)$ & $16(11-25)$ & 0.46 \\
\hline Years with T1D & & $18(6-27)$ & $11(6-20)$ & 0.078 \\
\hline Body mass index & & $25.6 \pm 4.5$ & $24.3 \pm 3.9$ & 0.072 \\
\hline \multirow[t]{2}{*}{ Glycated hemoglobin } & $\%$ & $8.7(7.9-9.8)$ & $8.5(7.6-9.1)$ & 0.068 \\
\hline & $\mathrm{mmol} / \mathrm{mol}$ & $71.6(62.8-83.6)$ & $69.4(59.5-76)$ & \\
\hline
\end{tabular}




\begin{tabular}{|c|c|c|c|}
\hline Variable & Eating disorder $(n=79)$ & Negative eating disorder $(n=87)$ & $\mathbf{p}$ \\
\hline \multicolumn{4}{|l|}{ Gender } \\
\hline Female & $51(64.6)$ & 38 (43.7) & 0.007 \\
\hline Skin color & & & 0.501 \\
\hline White & 65 (82.3) & 77 (88.5) & \\
\hline Black & $9(11.4)$ & $7(8)$ & \\
\hline Brown & $5(6.3)$ & $3(3.4)$ & \\
\hline Nephropathy & $57(72.2)$ & 70 (81.4) & 0.159 \\
\hline Neuropathy & $15(19)$ & $9(10.3)$ & 0.114 \\
\hline Vasculopathy & $7(8.9)$ & $4(4.6)$ & 0.27 \\
\hline Diabetic retinopathy & $34(43)$ & $20(23.0)$ & 0.011 \\
\hline Dyslipidemia & $22(27.8)$ & $13(14.9)$ & 0.042 \\
\hline Hypertension & $33(41.8)$ & $18(20.7)$ & 0.006 \\
\hline \multicolumn{4}{|l|}{ Hypoglycemia } \\
\hline Severe & $48(60.8)$ & $49(56.3)$ & 0.562 \\
\hline Frequent & $18(22.8)$ & $20(23)$ & 0.975 \\
\hline Nocturnal & $38(48.1)$ & $30(34.5)$ & 0.075 \\
\hline Previous ICU admission & $36(45.6)$ & 35 (40.2) & 0.487 \\
\hline Diabetes hospitalization & $46(58.2)$ & $51(58.6)$ & 0.959 \\
\hline Family support & $41(51.9)$ & $45(51.7)$ & 0.982 \\
\hline Physical activity & $36(52.9)$ & $32(47.1)$ & 0.25 \\
\hline Glucose self-monitoring & 73 (92.4) & $83(95.4)$ & 0.418 \\
\hline Psychological assessment & $51(64.6)$ & 38 (43.3) & 0.007 \\
\hline Psychiatric medication & $29(36.7)$ & $16(18.4)$ & 0.008 \\
\hline \multicolumn{4}{|l|}{ Drugs } \\
\hline Alcohol & $11(13.9)$ & $19(21.8)$ & 0.186 \\
\hline Cigarette & $5(6.3)$ & $11(12.6)$ & 0.169 \\
\hline Cocaine & $1(1.3)$ & $1(1.1)$ & 0.945 \\
\hline Suicidal & $21(26.6)$ & $15(17.2)$ & 0.145 \\
\hline $\mathrm{SCl}-\mathrm{R}>48$ & $50(63.3)$ & $41(47.1)$ & 0.037 \\
\hline B-PAID, punctuation & $42.5(27.5-65)$ & $35(11.2-57.5)$ & $<0.001$ \\
\hline Depression & $21(26.6)$ & $13(14.9)$ & 0.063 \\
\hline Anxiety & $34(43)$ & $33(37.9)$ & 0.503 \\
\hline
\end{tabular}

Data are presented as median (interquartile range), means \pm standard deviation and number of patients (percentual).

Psychiatric medication means current treatment. Psychological assessment corresponds to assessment at any time in the past.

1 Eating Attitudes Test -26 . values $\geq 21$ mean that patient is at risk of eating disorders.

Table 4. Demographic Characteristics of Type 1 Diabetic Patients at B-PAID ${ }^{1}$ Questionnaire $(n=166)$

\begin{tabular}{|c|c|c|c|c|}
\hline Variable & & Severe B-PAID ${ }^{2}(n=79)$ & Mild B-PAID $(n=87)$ & p \\
\hline Age, years & & $32(24-45)$ & $34(21-47)$ & 0.997 \\
\hline Age of diagnosis, years & & $18(12-25)$ & $16(11-26)$ & 0.231 \\
\hline Years with T1D & & $11(6-23)$ & $16(6-27)$ & 0.276 \\
\hline Body mass index & & $25.3 \pm 4.46$ & $24.6 \pm 4.01$ & 0.286 \\
\hline \multirow[t]{2}{*}{ Glycated hemoglobin } & $\%$ & $8.8(7.9-10.1)$ & $8.3(7.6-9.0)$ & 0.009 \\
\hline & $\mathrm{mmol} / \mathrm{mol}$ & $72.7(62.8-86.9)$ & $67.2(59.5-74.9)$ & \\
\hline \multicolumn{5}{|l|}{ Gender } \\
\hline Female & & $53(67.1)$ & $36(41.4)$ & $<0.001$ \\
\hline
\end{tabular}




\begin{tabular}{|c|c|c|c|}
\hline Variable & Severe B-PAID ${ }^{2}(n=79)$ & Mild B-PAID $(n=87)$ & p \\
\hline Skin Color & & & 0.442 \\
\hline White & 65 (82.3) & 77 (88.5) & \\
\hline Black & $10(12.7)$ & $6(6.9)$ & \\
\hline Brown & $4(5.1)$ & $4(4.6)$ & \\
\hline Nephropathy & $19(24.1)$ & $19(22.1)$ & 0.765 \\
\hline Neuropathy & $14(17.7)$ & $10(11.5)$ & 0.255 \\
\hline Vasculopathy & $5(6.3)$ & $6(6.9)$ & 0.883 \\
\hline Diabetic retinopathy & $24(30.4)$ & $30(34.5)$ & 0.524 \\
\hline Dyslipidemia & $14(17.7)$ & $21(24.1)$ & 0.311 \\
\hline Hypertension & $20(25.3)$ & $31(35.6)$ & 0.22 \\
\hline \multicolumn{4}{|l|}{ Hypoglycemia } \\
\hline Severe & $44(55.7)$ & $53(60.9)$ & 0.495 \\
\hline Frequent & $18(22.8)$ & $20(23)$ & 0.975 \\
\hline Nocturnal & $37(46.8)$ & $31(35.6)$ & 0.143 \\
\hline Previous ICU admission & 35 (44.3) & $36(41.4)$ & 0.704 \\
\hline Diabetes hospitalization & 47 (59.5) & $50(57.5)$ & 0.792 \\
\hline Family support & $45(57)$ & $41(47.1)$ & 0.205 \\
\hline Physical activity & $26(32.9)$ & $42(48.3)$ & 0.044 \\
\hline Glucose self-monitoring & $74(93.7)$ & $82(94.3)$ & 0.875 \\
\hline Psychological assessment & $49(62)$ & $40(46)$ & 0.038 \\
\hline Psychiatric medication & $32(40.5)$ & $13(14.9)$ & $<0.001$ \\
\hline \multicolumn{4}{|l|}{ Drugs } \\
\hline Alcohol & 13 (43.3) & 17 (56.7) & 0.606 \\
\hline Cigarette & 7 (8.9) & $9(10.3)$ & 0.746 \\
\hline Cocaine & $0(0.0)$ & $2(2.3)$ & 0.175 \\
\hline Suicidal & $27(34.2)$ & $9(10.3)$ & $<0.001$ \\
\hline $\mathrm{SCl}-\mathrm{R}>48$ & 36 (45.6) & 55 (63.2) & 0.022 \\
\hline EAT $\geq 21$ & $44(55.7)$ & 35 (40.2) & 0.046 \\
\hline Depression & 25 (31.6) & $9(10.3)$ & $<0.001$ \\
\hline Anxiety & 47 (59.5) & $20(23)$ & $<0.001$ \\
\hline
\end{tabular}

Data are presented as median (interquartile range), means \pm standard deviation and number of patients (percentual).

1 Brazilian Problem Areas in Diabetes Scale.

2 Values $\geq 40$ indicates a high level of emotional distress.

Psychiatric medication means current treatment. Psychological assessment corresponds to assessment at any time in the past.

\section{DISCUSSION}

Our study describes a cohort of TID patients in two tertiary care centers for patients with diabetes in southern Brazil. Our findings show that depressed patients with high suffering related to diabetes had worse glycemic control, although we did not observe an association between psychiatric disorder and the presence of chronic complications of TID.

In the present study, depressed patients are also more prone to severe hypoglycemia and a greater need for hospitalization due to the disease. Depressed patients were more prone to eating disorders. They also had less adherence to the proposed treatment and high levels of emotional distress related to TID (B-PAID). In addition, they had a significant suicidal behavior or ideation, mainly in women.

Anxiety was related to sedentary behavior and low adherence to daily glycemic self-monitoring. It was more frequent in females. Those with anxiety disorder had statistically higher emotional distress related to diabetes (B-PAID), which perhaps explains the $72.2 \%$ of anxious patients with some thought of ideation and in some cases even attempted suicide. In addition, anxiety was strongly related to low adherence to 
diabetes treatment, although not significant, which can probably be related to our sample size.

Regarding to prevalence, we observed $20.5 \%$ and $40.4 \%$ of depressed and anxious patients, respectively. While Maia and cols. reported only 13.6\% of depressed TID patients, using the Hospital Anxiety and Depression Scale (HADS) tool for diagnosis (25) and data from the meta-analysis by Buchberger and cols. reported depression in $30 \%$ of children and adolescents with TID (4). These disparities can be explained by different patient populations, however, all report significant numbers of these clinical conditions.

We found almost $55 \%$ of the screened sample with a positive result for some psychiatric disorder, of which $68 \%$ had already been evaluated by psychologists/ psychiatrists at some point in their lives and only $27 \%$ were using pharmacological treatment. It is known that underdiagnosed and, consequently, undertreated patients worsen the prognosis of diabetes-related outcomes $(6,14)$. In this context, psychological/psychiatric screening tools are essential for assess psychiatric pathologies. In our sample, the questionnaires detected about $1 / 3$ of the patients with positive screening for psychiatric illness, without ever having been evaluated by a mental health professional.

More adherent patients had better glycemic control, while high levels of diabetes-related suffering were associated with an increased risk of depression and anxiety. In anxious patients, the prevalence of physical inactivity was higher than in controls. In the context of evaluating psychiatric comorbidities, sedentary patients with high levels of emotional distress seem to be more likely to develop such pathologies, even before they express symptoms of depression or anxiety. Therefore, the active search for such a condition should be encouraged and even should be part of the screening for chronic complications of diabetes.

According to the ADA, physical exercise is recommended for every TID patient (26) and should be regularly stimulated. Our study demonstrated that the practice of regular physical activity was more frequent in the group without anxiety and was related to less psychological suffering related to diabetes and more adherence to the proposed clinical treatment (SCI-R).

The demands for self-care of TID increase the risk of developing psychiatric disorders (4-6). A frequent problem in clinical practice is that mental health professionals are not always readily available to perform a comprehensive analysis of the patients' psychological profile. In this scenario, screening questionnaires for depression, anxiety and eating disorders should be considered for use (26). We observed that almost half of the patients had positive screening for eating disorders, something that often neglected in routine medical care. Paradoxically, our patients with positive screening for eating disorder did not have a worsening of glycemic control, unlike all other psychiatric disorders assessed and several previous studies, which found worsening of glucose levels and an increased risk of hypoglycemia in patients with an eating disorder (27-29). As an example, Rydall and cols. found significantly higher HbAlc values $(11.2 \% \pm 1.2 \%$ or $99 \pm 10 \mathrm{mmol} / \mathrm{mol})$ in the group with severe eating disorder and TID in relation to patients with diabetes without the disorder $(8.7 \% \pm 1.7 \%$ or $72 \pm 5 \mathrm{mmol} / \mathrm{mol})(30)$.

Regarding the limitations, we carried out a crosssectional study, collecting some clinical data in medical records. Due to the design, we are limited in the definition of some vascular complications of diabetes, such as macrovascular disease and other comorbidities (hypertension, dyslipidemia and microvascular complications related to TID). The diagnostics made by simple record in the medical record. This may certainly have underestimated the actual number of patients with vascular complications and the potential risk of inadequate data filling. However, since both clinics are university centers specialized in diabetes, the medical record information is reliable. Furthermore, we do not estimate the relevance of neuropathic pain in the psychological health of the participants. When using self-administered questionnaires that assess diabetesrelated stress, we assumed the risk of misdiagnosing patients as depressed, which may have increased the frequency of depression, according to Roy and Lloyd (31). In addition, self-reported data can generate misleading results. Also, the lack of application of a more appropriate physical activity questionnaire underestimated our favorable finding regarding physical activity. We opted for the EAT-26 questionnaire because it was validated for the Brazilian population, even though it is not a specific tool for TID patients, wich may have generated distortions in the results given the diabetes particularities and made it impossible to evaluate the diabulimia disorder when someone reduces or stops taking their insulin to lose weight (28).

The strengths of our study were the multicenter design, a broad evaluation of psychiatric disorders, 
the use of well-validated questionnaires and the finding of a huge number of patients with TID have underdiagnosed and undertreated psychiatric disorders, which can impair glycemic control. Moreover, we found a high prevalence of eating disorders, psychiatric disorders and emotional distress related to type 1 diabetes. In particular, depression and elevated B-PAID were associated with worse glycemic control. Sedentary behavior and emotional distress or illness-related stress were associated with the presence of these pathologies. Therefore, medical care for psychiatric disorders should be encouraged by current guidelines and screening for these morbidities should be performed actively and early.

Contribution statement: TMF designed the study, collected data and authored the initial manuscript. TCR and LSW guided the research, contributed to the manuscript and provided statistical advice. IBD, JASC, IC and MPM participated in the data collection.

Acknowledgments: we would like to express our gratitude for the support of FIPE (Researchers Incentive Fund of Hospital de Clinicas de Porto Alegre), CNPq (National Council for Scientific and Technological Development) and Capes (Coordination for the Improvement of Higher Education Personnel). We are especially grateful to the patients who kindly participated in this study.

Funding: this research did not receive any specific grant from funding agencies in the public, commercial, or not-for-profit sectors.

Disclosure: no potential conflict of interest relevant to this article was reported.

\section{REFERENCES}

1. Miller KM, Foster NC, Beck RW, Bergensta RM, DuBose SN, DiMeglio LA, et al. Current state of type 1 diabetes treatment in the U.S.: Updated data from the t1d exchange clinic registry. Diabetes Care. 2015;38:971-8.

2. Cooper MN, Lin A, Alvares GA, de Klerk NH, Jones TW, Davis EA. Psychiatric disorders during early adulthood in those with childhood onset type 1 diabetes: Rates and clinical risk factors from population-based follow-up. Pediatr Diabetes. 2017;18:599-606.

3. World Health Organization (WHO). Depression and Other Common Mental Disorders: Global Health Estimates. Geneva: WHO; 2017.

4. Buchberger B, Huppertz H, Krabbe L, Lux B, Mattivi JT, Siafarikas A. Symptoms of depression and anxiety in youth with type 1 diabetes: A systematic review and meta-analysis. Psychoneuroendocrinology. 2016;70:70-84.

5. Almeida MC, Claudino DA, Grigolon RB, Fleitlich-Bilyk B, Claudino AM. Psychiatric disorders in adolescents with type 1 diabetes: $A$ case-control study. Rev Bras Psiquiatr. 2018;40:284-9.

6. Butwicka A, Frisén L, Almqvist C, Zethelius B, Lichtenstein P. Risks of Psychiatric disorders and suicide attempts in children and adolescents with type 1 diabetes: A population-based cohort study. Diabetes Care. 2015;38:453-9.

7. Snoek FJ, Bremmer MA, Hermanns N. Constructs of depression and distress in diabetes: Time for an appraisal. Lancet Diabetes Endocrinol. 2015;3:450-60.

8. Gonzalez JS, Fisher L, Polonsky WH. Depression in diabetes: Have we been missing something important? Diabetes Care. 2011;34:236-9.

9. American Diabetes Association. Standards of Medical Care in Diabetes. Diabetes Care. 2020;43(Suppl 1):S1-S2.

10. Cherubini V, Skrami E, lannilli A, Cesaretti A, Paparusso $\mathrm{AM}$, Alessandrelli $\mathrm{MC}$, et al. Disordered eating behaviors in adolescents with type 1 diabetes: A cross-sectional populationbased study in Italy. Int J Eat Disord. 2018;51:890-8.

11. Young-Hyman DL, Davis CL. Disordered eating behavior in individuals with diabetes: Importance of context, evaluation, and classification. Diabetes Care. 2010;33:683-9.

12. Doyle EA, Quinn SM, Ambrosino JM, Weyman K, Tamborlane WV, Jastreboff AM. Disordered Eating Behaviors in Emerging Adults with Type 1 Diabetes: A Common Problem for Both Men and Women. J Pediatr Health Care. 2017;31:327-33.

13. Young V, Eiser C, Johnson B, Brierley S, Epton T, Elliott J, et al. Eating problems in adolescents with Type1 diabetes: A systematic review with meta-analysis. Diabet Med. 2013;30:189-98.

14. Majidi S, O'Donnell HK, Stanek K, Youngkin E, Gomer T, Driscoll KA. Suicide risk assessment in youth and young adults with type 1 diabetes. Diabetes Care. 2020;43:343-8.

15. Gross CC, Scain SF, Scheffel R, Gross JL, Hutz CS. Brazilian version of the Problem Areas in Diabetes Scale (B-PAID): Validation and identification of individuals at high risk for emotional distress. Diabetes Res Clin Pract. 2007;76:455-9.

16. Bighetti F. Tradução e validação do Eating Attitudes Test (EAT-26) em adolescentes do sexo feminino na cidade de Ribeirão Preto SP [dissertação]. Ribeirão Preto: Universidade de São Paulo; 2003.

17. Teló GH, De Souza MS, Schaan BDA. Cross-cultural adaptation and validation to Brazilian Portuguese of two measuring adherence instruments for patients with type 1 diabetes. Diabetol Metab Syndr. 2014;6:1-6.

18. Tuttle KR, Bakris GL, Bilous RW, Chiang JL, De Boer IH, GoldsteinFuchs $\mathrm{J}$, et al. Diabetic kidney disease: $\mathrm{A}$ report from an ADA consensus conference. Diabetes Care. 2014;37:2864-83.

19. KDIGO. Clinical Practice Guideline for the Evaluation and Management of Chronic Kidney Disease. Kidney Int. 2013;3:S1S150.

20. Seaquist ER, Anderson J, Childs B, Cryer P, Dagogo-Jack S, Fish $L$, et al. Hypoglycemia and diabetes: A report of a workgroup of the American diabetes association and the endocrine society. Diabetes Care. 2013;36:1384-95.

21. Garner D, Garfinkel P. The Eating Attitudes Test an index of anorexia nervosa. Psychol Med. 1979:273-9.

22. Van Steenbergen-Weijenburg KM, De Vroege L, Ploeger RR, Brals JW, Vloedbeld MG, Veneman TF, et al. Validation of the PHQ-9 as a screening instrument for depression in diabetes patients in specialized outpatient clinics. BMC Health Serv Res. 2010;10:5-10.

23. Santos IS, Tavares BF, MunhozTN, de Almeida LSP, da Silva NTB, Tams BD, et al. Sensibilidade e especificidade do Patient Health Questionnaire-9 (PHQ-9) entre adultos da população geral. Cad Saude Publica. 2013;29:1533-43.

24. American Psychiatric Association (APA). Diagnostic and Statistical Manual of Mental Disorders, Fifth Edition (DSM-5). Arlington: APA; 2013.

25. Maia ACCO, Braga AA, Paes F, Machado S, Nardi AE, Silva AC. Psychiatric comorbidity in diabetes type 1: A cross-sectional observational study. Rev Assoc Med Bras. 2014;60:59-62. 
26. American Diabetes Association. Children and adolescents: Standards of Medical Care in Diabetes. Diabetes Care. 2020;S163-82.

27. Toni G, Berioli MG, Cerquiglini L, Ceccarini G, Grohmann U, Principi N, et al. Eating disorders and disordered eating symptoms in adolescents with type 1 diabetes. Nutrients. 2017;9:1-10.

28. Pinhas-Hamiel O, Hamiel U, Greenfield Y, Boyko V, Graph-Barel C, Rachmiel M, et al. Detecting intentional insulin omission for weight loss in girls with type 1 diabetes mellitus. Int J Eat Disord. 2013;46:819-25.
29. Schober E, Wagner G, Berger G, Gerber D, Mengl M, Sonnenstatter $S$, et al. Prevalence of intentional under- and overdosing of insulin in children and adolescents with type 1 diabetes. Pediatr Diabetes. 2011;12:627-31.

30. Rydall AC, Rodin GM, Olmsted MP, Devenyi RG, Daneman D. Disordered eating behavior and microvascular complications in young women with insulin-dependent diabetes mellitus. $\mathrm{N}$ Engl J Med. 1997;336:1849-54.

31. Roy T, Lloyd CE. Epidemiology of depression and diabetes: A systematic review. J Affect Disord. 2012;142:S8-21. 